\title{
Response to Letter regarding "Motor and functional outcome of selective dorsal rhizotomy in children with spastic diplegia at 12 and 24 months of follow-up"
}

\author{
Matthias Schulz ${ }^{1}$ D . Ulrich-Wilhelm Thomale ${ }^{1}$
}

Received: 1 November 2021 / Accepted: 2 November 2021 / Published online: 20 November 2021

(c) The Author(s) 2021

We thank the author for the letter about the published article from our institution about the motor and functional outcome after selective dorsal rhizotomy (SDR) and welcome the opportunity to further clarify aspects of the study's methods.

With the treatment armamentarium for children with spastic diplegia SDR might play a significant role to reduce the amount of spasticity and thereby establishing the possibility for improved ambulation and overall motor function. Infantile cerebral palsy (ICP) constitutes a situation with a lifelong effect; therefore any treatment - including SDR - will ideally establish an live-long improvement. Treatment efficacy should therefore be measured after the longest possible follow-up. Several studies have demonstrated long-term efficacy of SDR to reduce spasticity [1, 2]. In this regard, the follow-up of 24 months in the presented study is at a lower range but still meaningful. We will continuously follow all treated patients beyond this reported two-years period and aim for markedly longer clinical observation into adolescence.

As Dr. Özden correctly pointed out, there are several confounding factors, which might influence the amount of spasticity after SDR. However, similar to the situation at the preoperative evaluation for possible SDR, no patients were under the effect of botulinum toxin injection (botox) at re-evaluation or did receive any botox during that time. All patients underwent standardized inpatient rehabilitation at specialized pediatric rehabilitation hospitals for several weeks postoperatively. For practical reasons and to avoid

This article is part of the Topical Collection on Functional Neurosurgery

Matthias Schulz

matthias.schulz@charite.de

1 Pediatric Neurosurgery, Charité - Universitätsmedizin Berlin, Augustenburger Platz 1, 13353 Berlin, Germany travel of the families the additional subsequent outpatient rehabilitation was allocated to the local physiotherapist at the family's residential place.

The numerical data of the Modified Ashworth Scale (MAS, values of "1", "1+", "2", "3" and "4") as well of the Medical Research Council Scale (MRC, values of 0 to 5) represent data of an ordinal level. The median is the recommended measurement of central tendency of ordinal scales; mean and standard deviation represent data on a nominal level/scale and are better not applied to evaluate MAS and MRC scales. Likewise, the suggested paired Student's t-test usually requires normal distribution of the variables and continuous dependent variables on an interval scale. Based on the ordinal level of the evaluated scales the non-parametric test (e.g. Wilcoxon matched-pair signed-rank test) was utilized for the presented data.

We agree with the statement, that ideally the measurements of the MAS and MRC should be collected by the same clinician in order to avoid observer bias. However, with a large patient cohort this ambition became less practical in our setting. In consideration of possible observer bias and to minimize this effect within the collected data all pre- and postoperative assessments were performed by a restricted group of clinicians of the multidisciplinary SDR team with extensive experience in taking care of children with spasticity and ICP.

In the context of other reports on the beneficious effects of SDR on spasticity and function and in respect to the discussed methodological limitations we are confident that the presented study provides further evidence of the merit of SDR in children with spastic diplegia.

Funding Open Access funding enabled and organized by Projekt DEAL. 
Open Access This article is licensed under a Creative Commons Attribution 4.0 International License, which permits use, sharing, adaptation, distribution and reproduction in any medium or format, as long as you give appropriate credit to the original author(s) and the source, provide a link to the Creative Commons licence, and indicate if changes were made. The images or other third party material in this article are included in the article's Creative Commons licence, unless indicated otherwise in a credit line to the material. If material is not included in the article's Creative Commons licence and your intended use is not permitted by statutory regulation or exceeds the permitted use, you will need to obtain permission directly from the copyright holder. To view a copy of this licence, visit http://creativecommons.org/licenses/by/4.0/.

\section{References}

1. Ailon T, Beauchamp R, Miller S, Mortenson P, Kerr JM, Hengel AR, Steinbok P (2015) Long-term outcome after selective dorsal rhizotomy in children with spastic cerebral palsy. Childs Nerv Syst 31:415-423. https://doi.org/10.1007/s00381-015-2614-9

2. Dudley RW, Parolin M, Gagnon B, Saluja R, Yap R, Montpetit K, Ruck J, Poulin C, Cantin MA, Benaroch TE, Farmer JP (2013) Long-term functional benefits of selective dorsal rhizotomy for spastic cerebral palsy. J Neurosurg Pediatr 12:142-150. https:// doi.org/10.3171/2013.4.PEDS12539

Publisher's note Springer Nature remains neutral with regard to jurisdictional claims in published maps and institutional affiliations. 